\title{
As relações Colômbia, países vizinhos e Estados Unidos: visões em torno da agenda de segurança
}

Relations between Colombia, its neighbours and the United States: Views on the Security Agenda

Rev. Bras. Polít. Int. 48 (2): 86-110 [2005]

\section{Introdução}

Em 1991, como epitáfio do meio século de bipolaridade, a desintegração da União Soviética suprimiu o pólo oriental do sistema internacional vigente até então. O conjunto da geometria do espaço global da Guerra Fria foi radicalmente alterado, fazendo com que suas fronteiras ideológicas e geopolíticas perdessem significado. O fim da Guerra Fria acabou legando aos EUA a condição de única superpotência que reunia, simultaneamente, força militar e hegemonia estratégica global, o que provocou um debate sobre a configuração de poder que se sucederia à dissolução da URSS.

As visões do sistema pós-Guerra Fria variam da unipolaridade à multipolaridade e até mesmo ao hibridismo. $\mathrm{O}$ único consenso que parece existir hoje é que a questão da segurança internacional e as ameaças à segurança nacional não podem mais ser colocadas nos mesmos termos da Guerra Fria, pois passaram a ser vistas a partir de novas dimensōes neste começo de século. Fundamentalmente, poderíamos destacar o surgimento de novos atores e processos capazes de desestabilizar o sistema internacional por meios alternativos aos estratégico-militares convencionais. ${ }^{1}$

Nessa perspectiva de redefinição das ameaças à segurança nacional se encaixa a problemática de produção e tráfico de drogas na América Latina. Desde a administração Reagan (1980-1988), os EUA têm definido as drogas como um "problema de segurança nacional", cujo combate deveria ser feito

* Professor de Relaçôes Internacionais do Departamento de Ciência Política da Universidade de São Paulo - USP (rafaelvi@usp.br).

** Professora de Relações Internacionais da Universidade Nacional Autônoma do México (UNAM).

${ }^{1}$ Ver para estas temáticas: VILLA, Rafael Duarte. Da Crise do realismo á segurança global multidimensional. São Paulo: Annablueme/Fapesp, 1999, caps 4 e 5. 
por meio de um ataque contundente in locus à oferta da droga. Em outras palavras, a produção deveria ser atacada na fonte, em países como Bolívia, Colômbia, Equador e Peru. Partindo dessa premissa, desde a administração Bush pai (1989-1993), passa a integrar o vocabulário diplomático dos policymakers norte-americanos a expressão de efeito "guerra às drogas". Simultaneamente, em 1989, o governo Bush lançaria a National Drug Control Strategy, com a qual explicitou-se a "luta através do uso da política externa"2.

A invasão ao Panamá com o objetivo de capturar um antigo ex-aliado, Manuel Noriega, em dezembro de 1989, seria o grande ponto de inflexão por parte dos EUA na política de "tolerância zero" com as drogas. Tal marco representou que, a partir de então, o governo dos EUA estaria disposto a utilizar quaisquer meios - inclusive os militares - para atingir seu objetivo em relação ao combate ao narcotráfico. Após a captura de Noriega, a mensagem da política antidrogas norte-americana tornou-se cristalina: o tráfico de psicotrópicos ilegais passaria a ser interpretado pelo governo dos EUA como alvo primordial de sua segurança nacional. Por ser de preocupação fundamental, o narcotráfico deveria ser combatido com todas as forças, o que, para o governo de George Bush, essencialmente, significava "militarização".

Para os policy-makers norte-americanos, a política de going to the source "ir à fonte" - teria encontrado sólidos argumentos empíricos no caso de Chapare da Bolívia e do Alto Huallaga do Peru, onde eram cultivadas cerca de $80 \%$ a $90 \%$ das folhas de coca destinadas à alimentação da produção de cocaína no mundo ${ }^{3}$.

Desde o início da década de 1990, o eixo central dessa "Guerra às Drogas" transformou-se, então, no que passaria a ser conhecido como Estratégia Andina. Tal estratégia condensa quatro pontos fundamentais: fortalecimento das instituições políticas dos países chaves na oferta de drogas ilícitas (Bolívia, Colômbia e Peru); fortalecimento operacional de unidades militares e policiais encarregadas do combate ao circuito da droga (erradicação de cultivos, comércio de precursores químicos, destruição de laboratórios, interdição de drogas, detecção das rotas e criminalização da lavagem de dinheiro), assim como o assessoramento militar e policial direto aos países andinos para o desmantelamento de cartéis (Colômbia) e de firmas (Peru) de drogas. Este último item representa, mais especificamente para o caso colombiano, uma política de extradição de narcotraficantes. Finalmente, assistência comercial e fiscal para minimizar as conseqüências sociais decorrentes da privação de meios de subsistência de comunidades locais, como de fato ocorreu. Levando em

\footnotetext{
${ }^{2}$ De acordo com dados de Paul Kennedy, no início dos anos 90, os EUA, com apenas 5\% da população mundial, consumiam cerca de $50 \%$ da cocaína produzida no mundo. Ver: KENNEDY, Paul. Preparando para o século XXI. p. 308.

3 LESSMAN, Roberto. El narcotráfico y las relaciones internacionales. In Cuadernos de Nueva Sociedad.. Caracas: $\mathrm{n}^{\circ} 1,2^{\circ}$ semestre, 1997. p. 56.
} 
conta esses elementos este artigo se divide em três partes: na primeira examinamos alguns antecedentes nas relações contemporâneas entre a Colômbia e os EUA; numa segunda, examinamos a presença dos EUA na Colômbia por meio de mecanismos como o Plano Colômbia e a Iniciativa Regional Andina; e na terceira abordamos as tensas relaçôes entre a Colômbia e seus vizinhos.

\section{Relações contemporâneas entre Colômbia e os EUA: das tensões à cooperação}

Em relação à relação bilateral entre Colômbia e EUA, tendo como foco o problema das drogas, particularmente o narcotráfico, a Administração Clinton representa um momento em que mais se acumulam as tensões mas também aquele em que se começa a estabelecer as bases para um outro de cooperação diplomática irrestrita. Os momentos de tensão foram acumulando-se a partir de fatos ocorridos durante o governo do presidente César Gaviria (1990-1994), como na fuga de um dos chefes do narcotráfico, Pablo Escobar, então considerado como um dos homens mais procurados pelas autoridades colombianas e norte-americanas para julgamento e prisão nos EUA.

A reação do governo Clinton foi imediata, ao solicitar ao presidente Gaviria a criação de um dispositivo constitucional que permitisse a "extradição" de cidadãos colombianos em caso de delitos praticados no exterior e a intensificação das medidas de combate de forma a permitir a captura dos principais narcotraficantes. Em retaliação, os cartéis de drogas deram início a uma forte ofensiva terrorista no interior da Colômbia, atacando a burocracia nacional, especialmente os membros do Legislativo e do Judiciário.

Simultaneamente, vários incidentes, entre os quais destacamos o assassinato de importantes figuras públicas colombianas, provocaram a suspensão das conversas iniciadas pelo governo colombiano com a guerrilha das Forças Armadas Revolucionárias (Farcs) na Venezuela e no México. Como conseqüência, o conflito radicalizou-se, tendo em vista os constantes ataques perpetrados pelo exército colombiano nas zonas de refúgio da insurgência. Um exemplo relevante foi o ataque ao acampamento das Farcs em Casa Verde, então considerado a sede da Secretaria-Geral das Farcs. Ao ataque à Casa Verde, seguiram-se a intensificação das atividades armadas de grupos de milícia e a adoção de um programa governamental de incentivo à população para denúncia e oferta de informaçóes mediante pagamento de recompensas. O objetivo era obter, a todo custo, informações sobre o paradeiro de narcotraficantes, o que conduziria o país a uma espécie de "beco sem saída" em matéria de ordem pública.

Ao final de seu mandato de quatro anos, o então presidente Gaviria, vivendo em um ambiente de tensão extrema - ao ser pressionado, de um lado, por um governo em total estado de alerta contra todos os grupos de poder armados no país e, de outro, por constantes pressões por parte do governo 
norte-americano - lançaria uma dura ofensiva contra o Cartel de Cáli devido à injeção de recursos financeiros por este promovida em círculos políticos, tendo como exemplo mais extremo o financiamento de campanhas políticas para a eleição de representantes no Executivo. Obviamente, as estratégias de ação do Cartel de Cáli para obter maior influência no seio do governo nacional acabaram gerando uma situação muito complexa e tensa em relação a Washington, que se encontrava convencida de que haveria um vínculo direto entre o presidente recém eleito Ernesto Samper (1994-1998) e a máfia narcotraficante colombiana.

As denúncias de que a campanha de Samper, do partido liberal, havia sido financiada pelo dinheiro do narcotráfico, teria levado, nas palavras de uma analista político de então, "a nação, e não só o Estado, à beira do colapso integral: político, diplomático, militar, econômico e moral". ${ }^{4} \mathrm{O}$ efeito dessas acusaçōes foi devastador sobre a sociedade, que se viu dividida entre aqueles que apoiavam o presidente e aqueles que pregavam sua saída. Externamente, os EUA tomaram a decisão de classificar a Colômbia como uma "narcodemocracia”, o que provocaria um isolamento internacional da Colômbia de tal forma que o relacionamento diplomático entre os EUA e a Colômbia conduzir-se-ia, nos anos seguintes, pela mediação do diretor nacional da Polícia. Tamanha desmoralização internacional refletiu-se também nas próprias fileiras do exército, que passaram a mostrar pouca eficácia no combate aos grupos guerrilheiros.

$\mathrm{Na}$ esfera política, o evidente distanciamento e a falta de diálogo entre o então presidente norte-americano e o recém eleito presidente colombiano e seu novo gabinete dominaram as relaçóes EUA-Colômbia durante boa parte de seu mandato. Podemos destacar como exemplo da deterioração nas relaçôes bilaterais, a proibição do ingresso de funcionários do governo colombiano em território norte-americano mediante ao cancelamento de vistos de entrada. Dessa forma, após três anos consecutivos de "não-certificação" devido aos fracos resultados exibidos no combate ao narcotráfico, a Colômbia passou a sofrer sanções econômicas que produziriam reações encontradas em outros setores fora do governo.

Dispostos a mostrar boa vontade com relação aos EUA e ao combate ao narcotráfico, em 1995, o governo colombiano, liderado por Samper, procedeu à erradicação maciça do cultivo de folhas de coca. De 3.741 hectares erradicados em 1994, aumento para 23.402 no ano seguinte. No entanto, a produção cresceu de 44.700 hectares para 50.900 no mesmo ano. Nos anos seguintes, (1996 e 1997), a área erradicada totalizou aproximadamente 66.660, apesar da produção ter disparado para 146.700 hectares, índice praticamente inalterado mantido até 2000, colocando a Colômbia atualmente como o

${ }^{4}$ RESTREPO, Luis Alberto. La difícil recomposición de Colombia. In: Nueva Sociedad. Caracas: ${ }^{\circ}{ }^{192}$, julio-agosto, 2004. p. 46. 
principal exportador de coca e heroína para os EUA (80\% do total contrabandeado para aquele país $)^{5}$.

Simultaneamente, o governo norte-americano passou a aplicar uma drástica política migratória com o objetivo de frear o ingresso de colombianos em seu território. Uma das iniciativas adotadas foi o cancelamento de vistos concedidos a funcionários de alto escalão do governo colombiano, inclusive do gabinete presidencial. Tal retaliação terminaria por acelerar a deterioração e queda da imagem da Colômbia no exterior. Enquanto isso, no plano interno, uma opinião pública refratária às políticas e iniciativas governamentais de então impulsionaram o descontentamento social, situação inflamada pelo acúmulo de outros problemas como desemprego, insegurança, o clima generalizado de violência. Enfim, estava formado um ambiente que obstruiria quaisquer avanços em favor da pacificação dos conflitos armados.

Em um clima tenso de relações bilaterais EUA-Colômbia, os grupos armados acabariam aproveitando-se do momento de instabilidade dominante no país. Durante os quase quatro anos de polêmicas, procedimentos judiciais e parlamentares contra o presidente Samper e seu gabinete, os grupos armados acabaram conquistando importantes espaços políticos, nos quais foram capazes de levar a cabo ações de caráter político-militar. Como reação, membros do Exército Colombiano alertaram as autoridades norte-americanas acerca das implicaçôes decorrentes da "não-certificação" da Colômbia por três anos seguidos, o que acabou reduzindo a assistência externa no combate ao narcotráfico. A partir de então, o Exército Colombiano foi capaz de argumentar e convencer a Administração Clinton da existência de uma ligação estreita entre narcotráfico e guerrilha, oferecendo como exemplo o "cartel das Farcs" 6 .

De seu lado, as Farcs recusaram-se reconhecer ao governo de então qualquer legitimidade, não apenas ignorando a possibilidade do governo servir de interlocutor na pacificação, mas praticamente condicionando qualquer proposta de negociação à renúncia do presidente Samper ${ }^{7}$. Tal radicalização significou, em termos reais, o progressivo aumento da presença guerrilheira no território nacional, que passou de 17,2\% dos municípios sob seu controle em 1985 para $59,8 \%$ em $1995^{\circ}$.

Nesse período, as Farcs experimentaram seu maior crescimento numérico no país (calculava-se em 20.000 o número de efetivos), chegando inclusive a

\footnotetext{
${ }^{5}$ ROJAS, Diana Marcela \& ATEHORTUA, Adolfo. El Proceso de paz y el Plan Colombia. In: El Plan Colombia y la Internacionalización del conflicto. p. 121.

${ }^{6}$ FRANCO, Andrés. La Cooperación fragmentada como una nueva forma de diplomacia: las relaciones entre Colombia y Estados Unidos en los noventa. In: ANDRÉS, Franco (ed.). Estados Unidos y los paises andinos, 1993-1997: poder y desintegración. p.50.

7 GONZÁLEZ, Jiménez \& RAFAEL, Oscar. Colombia, ¿Negociación, arte por aprender?. In CHACÓN, Susana (coord.). Negociaciones diplomáticas: ¿un arte olvidado? Tecnológico de Monterrey, México, 2003. p. $138-139$.

${ }^{8}$ OSTOS, Maria del Pilar. Continuidad o cambio?: La participación de México en el conflicto armado colombiano. Mimeo, Cidade de México, p. 9.
} 
viabilizar-se como opção real de poder, fazendo com que alguns governos da América Latina e da Europa reconhecessem alguma representatividade ao permitir o funcionamento de algum tipo de representação da organização. Além disso, para complementar o quadro dramático, a economia colombiana, que havia conseguido fugir da "década perdida" da América Latina, experimentaria sua primeira recessão econômica em mais de setenta anos. Em resumo, o cenário era praticamente de colapso e o país parecia à beira de uma guerra civil intensa. Se no Equador a crise econômica dos últimos anos forçou milhares de pessoas a abandonar o país, na Colômbia, desde o governo Samper, devido ao conflito civil, milhares de colombianos fugiam para outros países à procura de segurança física e institucional.

Simultaneamente, outros grupos como os para-militares, a exemplo das Autodefesas da Colômbia (AUC), conseguiram consolidar sua atividade em alguns lugares de território colombiano graças aos próprios erros do governo colombiano. O reconhecimento outorgado pelo governo Samper para a criação de cooperativas rurais de segurança privada - chamadas Convivir - logo se converteram em organizações para-militares, impedindo rapidamente qualquer possibilidade em favor da pacificação. No entanto, o único avanço positivo durante o governo Samper em relação à pacificação interna dar-se-ia somente a partir da ratificação do Protocolo II de Genebra, no qual, pela Lei no 171 de dezembro de 1994, a Colômbia aderiu ao Protocolo sobre a Humanização do Conflito Armado ou Proteção da População Civil. Tal medida não apenas permitiu a investigação de violações de direitos humanos nas quais o Estado aceitaria sua responsabilidade, como também à criação da Comissão de Direitos Humanos e a reforma do código penal militar colombiano.

Em 1998, com a mudança de governo na Colômbia, assumiu a presidência o conservador Andrés Pastrana, então comprometido a resolver pacificamente o conflito armado negociando com a guerrilha e envolvendo a comunidade internacional na mediação do conflito. Além disso, Pastrana propunha o restabelecimento das relações com Washington, por ele considerado o mais importante aliado para a pacificação e estabilização da Colômbia.

Pelas razóes já citadas, tanto do ponto de vista interno quanto externo, a aproximação tentada por Pastrana durante sua campanha eleitoral com membros do Secretariado das Farcs objetivava retomar as conversações de pacificação rompidas durante o governo Gaviria a partir das incursões armadas do exército nacional na região de Uribe-Meta. O resultado dos primeiros encontros permitiu que, no final de 1998, ambas as partes, governo e guerrilha, definissem um local de encontro para conversação em uma área logo denominada de "zona de despejo”, na região de Meta, sem a presença do exército nacional e da polícia. ${ }^{9}$

\footnotetext{
${ }^{9}$ As Farcs condicionaram o início das negociações à retirada do Batalhão de Infantaria "Cazadores", então localizados em San Vicente del Caguán.
} 
Àquela localidade dirigiram-se políticos, empresários, associações campesinas, indígenas e estudantes, além de representantes oficiais de organizações não-governamentais internacionais com o objetivo de fazer conhecer suas propostas e demandas para o desenvolvimento de uma agenda de negociação de pacificação, sem, no entanto, deixar de verificar as condições e garantias do processo de paz. A partir desse momento, inaugura-se uma nova fase caracterizada por uma "política de mão dupla", sobretudo no governo seguinte ao de Pastrana, consolidando-se a negociação com as Farcs e os EUA fazendo-se cada vez mais visível no âmbito político-militar.

O governo do conservador Andrés Pastrana (1999-2002) iniciou a difícil tarefa de relegitimar o sistema político tanto interna como externamente. No nível doméstico, não obteve tanto sucesso, em parte devido ao fracasso do processo de pacificação interna junto aos grupos guerrilheiros, sobretudo as Farcs (às quais, inclusive, chegou a conceder uma zona desmilitarizada equivalente a $40 \%$ do território nacional), à falta de recuperação econômica e ao desborde de violência política no final de seu mandato. No nível externo, Pastrana teve sucesso em restabelecer plenamente as relaçóes com os EUA, aceitando, no entanto, a internacionalização do conflito colombiano e da luta ao narcotráfico por meio de mecanismos concretos como o Plano Colômbia, do qual falaremos mais adiante.

Nessas condições emerge, de uma divisão do Partido Liberal, Álvaro Uribe com o propósito de reunificar um país politicamente fragmentado. Para tanto, no plano externo, o governo de Uribe se propôs ao que chamou de "política de segurança democrática", concebida com três grandes objetivos: primeiro, a consolidação do território nacional ${ }^{10}$, com destaque para o papel das forças armadas e uma desmobilização dos grupos paramilitares; segundo, a eliminação do narcotráfico por meio do fortalecimento de políticas de fumigação das zonas de plantio e de combate pelo exército aos grupos de narcotraficantes; e terceiro, a proteção das fronteiras, por meio de acordos com os países vizinhos.

Tal política parece ter tido alguns resultados positivos e de proveito para o governo Uribe. A ampla ofensiva militar deflagrada contra os grupos guerrilheiros levou alguns analistas colombianos a admitir que, pela primeira vez em mais de cinquenta anos de conflitos, as Farcs e o Exército de Libertação Nacional se encontravam seriamente enfraquecidos política e militarmente. "A hora do guerrilheiro heróico, que há tantos anos já passou pela América Latina, começou também sua contagem regressiva na Colômbia". ${ }^{11}$ Por outro lado, Uribe soube capitalizar os resultados de sua política de "segurança democrática" ${ }^{2}$, recebendo por isso um amplíssimo apoio da população

\footnotetext{
${ }^{10}$ LEONGOMEZ, Eduard Pizarro. Una luz al final del tunel. Balanace estratégico del conflicto armado en Colombia. In: Nueva Sociedad. Caracas: no 192, jul-ago, 2004. p. 76.

${ }^{11} \mathrm{O}$ Núcleo dessa política são as Zonas de Reabilitação e Consolidação (ZRC), que incluem uma presença militar ativa e uma política de coordenação das zonas em conjunto com governadores e prefeitos.

${ }^{12}$ Luis Alberto Restrepo, op. cit., p. 50.
} 
colombiana, que enxergava em seu governo o grande responsável pela recuperação da legitimidade de um Estado que até o ano de 2002 encontravase à beira do abismo.

A atitude da população colombiana, cansada de tantos anos de conflito, mostra sua disposição em ignorar os imensos custos políticos da solução Uribe, que surgem como conseqüência dos excessos da aplicação de políticas repressivas de segurança interna que tendem a violar os direitos humanos de parte da população civil estabelecida nas zonas de conflitos entre exército e guerrilha. Num verdadeiro trade-off entre segurança e paz, Uribe buscou uma estreita aliança com os EUA, o que incluiu uma declaração explícita de apoio à Guerra do Iraque. Como sustenta Luis Alberto Restrepo, "Uribe tem colocado toda a política exterior a serviço da segurança. E, embora de imediato tenha obtido importantes êxitos políticos, financeiros e militares, sua estratégia hipoteca as relações internacionais da Colômbia, sobretudo com os vizinhos". ${ }^{13}$ No entanto, devemos reconhecer que se trata de, pelo menos, uma política com suficiente legitimidade - relativamente falando, considerando-se os governos anteriores - e que obteve respaldo em uma sociedade colombiana cansada de um extenuante conflito civil.

\section{A participação dos EUA no conflito colombiano: Plano Colômbia e estratégia Regional Andina}

Quando Pastrana decidiu chamar para si o compromisso de restabelecer os canais de diálogo com Washington, solicitou recursos financeiros ao Executivo norte-americano com o objetivo de avançar nas negociaçôes com as Farcs e continuar com o combate ao flagelo das drogas, ambos temas prioritários em sua plataforma de governo. Tal tentativa de contato foi por ele denominada de "diplomacia pela paz", que posteriormente tomaria corpo com a proposta do Plano Colômbia, que, segundo o próprio governo, representaria uma espécie de Plano Marshall de ajuda econômica e social destinado às zonas rurais afetadas pelo conflito. Essa iniciativa seria conduzida com apoio do governo norteamericano, o qual, durante os primeiros meses da presidência de Pastrana, manteve um intercâmbio de visitas de funcionários do alto escalão de ambos governos. Tal situação acabou muita bem interpretada por setores de direita e pela oligarquia colombiana.

Com as relações bilaterais entre EUA e Colômbia menos tensas, foi formulado o Plano Colômbia, cuja primeira versão foi apresentada em inglês. Segundo o Executivo colombiano, o Plano Colômbia destinava-se a ser um "plano para a paz, prosperidade e fortalecimento do Estado", destinando cerca

13 GARRIDO, Roberto Soberón. Entre cuarteles, caletas y fonteras. In: Cuadernos de Nueva Sociedad. Caracas: $\mathrm{n}^{\circ} 1,2^{\circ}$ semestre, 1997 , p. 85 
de $76 \%$ de seus recursos provenientes de crédito externo ao investimento social, e o restante direcionado ao combate ao narcotráfico como uma das prioridades do governo. Inicialmente, a iniciativa norte-americana foi projetada como um mecanismo militar de combate à produção e ao tráfico de drogas ilegais na Colômbia e em outros países da região andina.

Não devemos esquecer, no entanto, que a cooperação entre Colômbia, países andinos e os EUA sempre foi intensa durante a Administração Reagan (1980-1988), envolvendo a assinatura de acordos para o fornecimento de equipamentos, treinamento de militares e de policiais, além da presença de assessores norte-americanos. A partir de 1988, percebe-se que "em cada Estratégia Anual [antidrogas] tem-se incluído a variável do uso das FFAA nas tarefas antidrogas" 14 . No entanto, a entrada em vigor do Plano Colômbia pressupunha um envolvimento mais direto do governo norte-americano no combate ao narcotráfico. Nas palavras de Bonilla, a "aproximação realista que acompanha a prática das estratégias antidrogas do Departamento de Estado era focada na interdição e no controle", não podendo, portanto, ser eficaz, pois que "supõe capacidades que os Estados andinos particularmente não têm"15.

A partir de um sólido consenso bipartidário entre democratas e republicanos, o Congresso dos EUA aprovou em 1999 o Plano Colômbia. A proposta, de 7,5 bilhōes de dólares, apresenta três componentes: primeiro, a aproximação do Estado colombiano com as populaçóes afetadas pela violência por meio de investimentos sociais e substituição de plantios de coca, devendo o governo disponibilizar 4 bilhōes de dólares para esse fim; segundo, assistência técnica, militar e financeira dos EUA, no montante de 1,3 bilhão de dólares, para o combate ao narcotráfico em toda região andina, especialmente na Colômbia. Desses recursos, cerca de 55\% foram dirigidos às forças armadas e $27 \%$ à polícia, enquanto que os projetos de desenvolvimento alternativo obtiveram somente $9 \%$ dos recursos, assistência a deslocados, 3\%, reforma judicial, $2 \%$, proteção de direitos humanos, $1 \%$, e recursos para a paz, menos de $1 \%{ }^{16}$. Na realidade, somente 180 milhões de dólares seriam destinados aos vizinhos colombianos ${ }^{17}$. Finalmente, como último componente,

\footnotetext{
${ }^{14}$ BONILLA, Adrián. Percepciones de la amenaza de seguridad nacional de los países andinos: regionalización del conflicto colombiano y narcotráfico. In: GÓMEZ, José Maria (Comp.). América Latina y el (des)orden global neoliberal. Hegemonía, contrahegemonía, perspectivas. p. 185

15 OSTOS, María del Pilar. La Politica de Estado de Estados Unidos en Colombia (1980-2004). Mimeo. Cidade de México, 2005, p. 24.

16 "A administração Clinton propôs redirecionar 67\% do fundo do Plano Colômbia para a Colômbia. Desse total, 7\% eram para implementar três batalhôes militares antidrogas no sul da Colômbia, equipados com helicópteros. Suas missōes eram dar apoio aos planos de erradicação com pressão militar sobre as guerrilhas e grupos paramilitares diretamente ligados às operaçôes de tráfico de drogas". Ver: International Crisis Group. Colômbia e seus vizinhos: os tentáculos da instabilidade. In: Relatório sobre a América Latina. Bogota: IGC, n 7, 2003.

17 TOKATLIÁN, Juan Gabriel. El plan Colombia. De la Guerra interna la intervención internacional?. In: Anuario Social y político de América Latina y el Caribe. Flacso/Nueva Sociedad, no 4. p. 81.
} 
contribuição européia para a paz ${ }^{18}$. O fato é que nem todos os recursos financeiros previstos na assistência norte-americana chegaram a entrar no país. Conforme observou Anzola, "uma grande parte ficará para a compra de material bélico em empresas norte-americanas e para a contratação de mercenários deste país que virão a combater na Colômbia" ${ }^{19}$.

Certamente, o planejamento e a aplicação do Plano Colômbia foram facilitados pela visão da maior parte dos governantes andinos sobre a natureza transnacional da problemática do narcotráfico: "A percepção dos Estados andinos, especialmente a que se tem generalizado na Colômbia, é a de que o narcotráfico não é um tema que possa ser administrado essencialmente como política interior ou como simples capacidade de Estado" 20 .

Dois anos antes da implantação do Plano Colômbia, a administração Clinton assinaria em 1998 um acordo com o Equador para a transformação da base área de Manta (no noroeste do litoral equatoriano) em uma base avançada de operações dos EUA. Supóe-se que aproximadamente quinhentos soldados e agentes de inteligência norte-americanos estariam alocados naquela base para monitorar aviōes e plantações ilícitas na região sudoeste da Colômbia ${ }^{21}$. Esse posicionamento geoestratégico tem levado alguns autores a levantar a tese que a princípio pode parecer exagerada - de que a combinação entre militarização do combate ao narcotráfico e Plano Colômbia estaria operando uma redefinição dos interesses norte-americanos na América Latina. Seria uma estratégia em que Washington, já dominando seu mare nostrum caribenho, procuraria agora um controle efetivo dos Andes, "essa terra nossa da América do Sul"22.

Sem entrar no mérito da hipótese, não podemos ignorar que o Plano Colômbia e a presença de fuzileiros navais norte-americanos na base de Manta colocaram a região dos Andes num patamar de alta visibilidade nos aspectos relacionados com a segurança regional. $\mathrm{O}$ cenário demonstra, de um lado, que sucessivas administraçōes norte-americanas são capazes de aplicar medidas enérgicas na "guerra contra as drogas", fazendo com que ações sejam acompanhadas por uma diplomacia que procura atenuar as críticas daqueles que interpretaram o Plano Colômbia, desde os primeiros dias de seu anúncio, como o início de um novo Vietnã.

Por razões inerentes à estratégia de seguridade e à geoestratégia dos EUA, o pacote de ajuda aprovado pelo Congresso norte-americano para a luta

\footnotetext{
${ }^{18}$ ANZOLA, Libardo Sarmiento. O Plano Colombia e a economia política da guerra. In: Política Externa. São Paulo: USP/Paz e Terra, no 9, vol. 3, dezembro-janeiro, 2000/2001, p. 79.

19 BONILLA, Adrián. Percepciones de la amenaza de seguridad nacional de los países andinos: regionalización del conflicto colombiano y narcotráfico. In: GÓMEZ, José Maria (Comp.). América Latina y el (des)orden global neoliberal. Hegemonía, contrahegemonía, perspectivas. p. 154.

20 Supõe-se que boa parte da droga processada na Colômbia saia pelo litoral equatoriano rumo aos EUA, assim como $50 \%$ da munição para os grupos guerrilheiros e paramilitares colombianos entra na Colômbia também pela mesma via do litoral (El Espectador, 10.2.2003, "Desvían a las Farcs explosivos militares"). 21 TOKATLIÁN, Juan Gabriel. op. cit., p. 82.

22 GARCÍA. Andelfo. Plan Colombia y ayuda estadounidense. in: El Plan Colombia y la Internacionalización del conflicto, p. 262-263.
} 
antidrogas na Colômbia e para a exploração dos recursos naturais adquiriu uma dimensão transnacional (que incluiu, além do setor empresarial, os meios de comunicação, thinks tanks e organizações não-governamentais) e regional, com as respectivas repercussões para os países vizinhos à Colômbia, como é o caso da Venezuela e Equador.

Assim, o lobby político do empresariado norte-americano durante o processo de aprovação dos recursos econômicos para o Plano Colômbia no Congresso esteve sob o comando de empresas importantes como a United Technologies, Textron, Locheed Martin, Sikorsky, Bell, DynCorp e Military Prossesional Resources Inc. (MPRI), entre outras. Essas empresas dedicam-se ao comércio de armas, fabricação de helicópteros, radares e serviços de satélites, bem como ao treinamento de pessoal para tarefas de inteligência e manutenção de aparelhos aéreos para fumigar áreas de cultura da folha de coca e de papoula.

Esse tipo de lobby político-empresarial - ao funcionar como uma espécie de "terceirização de interesses" - também mantém uma ligação estreita com os representantes políticos dos diferentes estados da União, os quais, no interior dos EUA, servem de base para cada uma dessas empresas. Tal fato acaba gerando postos de trabalho e privilégios que ganham relevância em períodos eleitorais.

Isso explica a manipulação política de senadores, como ocorreu no estado de Connecticut, sede da empresa United Technologies, cuja filial Sikorsky fabrica os helicópteros de artilharia Black Hawk utilizados pela Força Aérea colombiana. $\mathrm{O}$ mesmo ocorreu com senadores texanos que favoreceram a empresa Textron, fabricante dos helicópteros Huey, outro conhecido no meio colombiano. A Lockheed Martin, outra empresa especializada no fornecimento de equipamento de monitoramento aéreo via satélite para identificação de áreas de cultivo de folha de $\operatorname{coca}^{23}$, assim como a DynCorp e a Military Prossesional Resources Inc. (MPRI), todas recebem o apoio da bancada do estado da Virginia.

Outro setor privado representante do lobby a favor da assistência à Colômbia é o consórcio US Colombia Business Partnership, liderado por empresas petrolíferas $^{24}$ ameaçadas por grupos armados colombianos. Elas são vítimas de ataques em suas áreas de operação: oleodutos, maquinaria e seqüestro de funcionários. Dessa forma, o consórcio petrolífero, formado por empresas norteamericanas como a Occidental Petroleum Company (OXY), Texaco, Chevron,

\footnotetext{
${ }^{23} \mathrm{O}$ potencial petrolífero (petróleo e gás natural) colombiano é calculado em mais de 37 bilhōes de barris. Da mesma forma, as bacias de maior atividade exploratória encontram-se nas regiōes altas e médias do Magdalena, Catatumbo, Guajira, Cordilheira Oriental, Putumayo e nos Planaltos Orientais. A Colômbia ocupa a quarta posição, atrás da Venezuela, México e Brasil, na produção de petróleo na América Latina. Finalmente, cerca de $80 \%$ de sua produção é exportada para os EUA. Ver: El Petróleo en Colombia. Disponível em: < http://www.ecopetrol.com.co/prin/petroleo/petroleo.htm>.

$24 \mathrm{O}$ tema é controverso. Ao contrário de Meza, outros estudiosos do conflito colombiano, como Fernando Ulloa, afirmam que, inclusive durante o mandato de Uribe, já havia sido registrado uma redução de $30 \%$ das plantações e sem as controvérsias que, tradicionalmente, surgem em torno dessas cifras. Ver: ULLOA, Fernando. Álvaro Uribe: dissidente. In: Politica Externa. São Paulo: USP/Paz e Terra, no 12, vol. 2, setembro-novembro, p.101, 2003.
} 
a inglesa British Petroleum e outras empresas canadenses e espanholas com importantes investimentos na Colômbia, têm pressionado o governo para obter mais proteção.

Por outro lado, a influência dos meios de comunicação, especialmente da imprensa escrita nos EUA, também foi fundamental para gerar uma forte opinião pública - seja favorável ou contrária - à alocação de recursos para o pacote de assistência à segurança colombiana nos últimos anos. Assim, enquanto o jornal The New York Times sugeria um menor envolvimento de Washington no conflito colombiano, o The Washington Post, mesmo de forma cautelosa, mostrou-se a favor do plano de assistência ao governo colombiano, entendendo necessário combater os efeitos do conflito armado e do narcotráfico. Já o Miami Herald favoreceu abertamente a aprovação de recursos para o Plano Colômbia.

Por outro lado, as discussōes no interior dos think tanks norte-americanos também fazem parte dessa grande rede que, além de manipular a opinião pública, define os interesses políticos e a tomada de decisões nos EUA. Por isso, é importante destacar o papel desempenhado por um grupo de intelectuais que, desde a administração Reagan, integraram os centros Diálogo Interamericano, Council on Foreign Relations, Heritage Foundation, US Army War College e o Strategic Studies Institute. São locais que até hoje produzem os mais importantes documentos para a gestão geopolítica e estratégica dos EUA na regiāo. O mais importante documento sobre o assunto é o Santa Fé I e IV, que expõe a base conceitual para o crescimento do terrorismo de Estado e das guerras de baixa intensidade, para a Doutrina de Segurança Nacional, a guerra preventiva, a ameaça anti-hegemônica, o apoio ao neoliberalismo, a vigência da Doutrina Monroe, entre outros.

Além disso, surgiram organizações com outra matriz como o Center for Internacional Policy (CIP) e o National Center for Policy Analysis (NCPA), que se opuseram ao pacote de assistência oferecido por Washington. Esses grupos entendem que, em vez de minimizar o conflito, a proposta norte-americana acabaria piorando a situação. Tal entendimento também é compartilhado por outras organizaçôes como o Human Rights Wacht e o WOLA, dois importantes atores não-estatais dedicados ao monitoramento e denúncia de violaçôes de direitos humanos na Colômbia, principalmente por parte de atores governamentais como o Exército colombiano, o maior beneficiado com os recursos financeiros e logísticos oferecidos pelos EUA.

Com relação à erradicação do cultivo em si, os resultados preliminares do Plano Colômbia parecem deixar algum saldo positivo, tendo em vista os dados fornecidos pelo próprio governo dos EUA, da Colômbia e da ONU. Apesar da aparente discordância de alguns pesquisadores como $\mathrm{Meza}^{25}$, os dados mostram uma redução, em mais de $50 \%$, do cultivo de coca no sul da Colômbia. Nessa

25 Ultimas Noticias, Analizarán el Plan Colômbia. 19 nov 2004. 
região, o cultivo caiu de 80 mil para 40 mil hectares entre 2001 e 2002. Segundo dados da ONU, o biênio 2001-2002 experimentou uma redução de $30 \%$ da área cultivada de coca nas diferentes regióes do país. Em 2004 o próprio governo colombiano anunciou que, na região da fronteira nordeste com a Venezuela, de 35 mil hectares em 2001 restavam somente 3 mil $^{26}$.

Obviamente, a aplicação do Plano Colômbia mudou o clima das conversações com a guerrilha e abriu uma dura polêmica entre os diferentes setores no interior do país. Nesse sentido, as Farcs denunciaram que o plano norte-americano constituía uma nova forma de intervenção dos EUA nos assuntos internos da Colômbia e agora sob a anuência da classe política e empresarial nacional. Além disso, as Farcs desconfiam que o pacote de assistência financiado pelos EUA tenha como objetivo real o rearmamento do Exército colombiano e intensificação da contraguerrilha para o combate ao narcotráfico.

Simultaneamente em que o debate e a controvérsia sobre o Plano Colômbia crescia, o Grupo de Apoyo al Proceso de Paz - formado por 22 países, na maioria latino-americanos e europeus ${ }^{27}$ - tentava dar um último empurrão às negociações e aos encontros entre o governo Pastrana e as Farcs com o apoio dos Estados Unidos. No entanto, a aproximação inicial entre governo e guerrilha foi rompida com o assassinato de três ativistas norte-americanos que trabalhavam com um grupo indígena na região de Arauca. Trata-se de uma área bastante conhecida por abrigar importantes poços de petróleo, onde funcionava a petrolífera norte-americana Occidental Petroleum Inc.

Este último fato produziu uma mudança na política externa dos EUA, fazendo-se sentir por sua ambigüidade: de um lado, apoio incondicional ao processo de paz, de outro, uma ênfase especial no componente militar. A falta de consenso em temas substantivos da agenda de negociação, a disputa militar entre a insurgência e os paramilitares, assim como a presença militar norteamericana com seus modernos batalhões e equipamento para a destruição de cultivos ilícitos em áreas de selva com presença guerrilheira e paramilitar levaram a um novo fracasso do processo de pacificação com as Farcs. Como conseqüência, e em sintonia com a concepção norte-americana do conflito colombiano, identificamos a adoção de políticas com um alto conteúdo militar para liquidar a insurgência ou, pelo menos, controlá-la e limitar suas ligações com o narcotráfico e o comércio de seqüestros.

Os acontecimentos de 11 de Setembro de 2001 significaram uma mudança de ênfase no relacionamento da política externa dos EUA com a Colômbia e a

\footnotetext{
${ }^{26}$ Alemanha, Áustria, Bélgica, Brasil, Canadá, Cuba, Chile, Dinamarca, Equador, Espanha, Finlândia, França, Itália, Japão, México, Noruega, Panamá, Holanda, Portugal, Santa Sé, Suíça, Venezuela, o representante da União Européia, o Assessor Especial do Secretário Geral das Nações Unidas para Assistência Internacional à Colômbia, a Diretora do Departamento de Assuntos Políticos para a América Latina e o Caribe da ONU, e o Diretor do Programa da ONU para Desenvolvimento.

${ }^{27}$ SAMPER, Ernesto. Ernesto Samper: gobernabilidad sin soberanía no vale la pena. In: ARCHARD, Diego e FLORES, Manuel. Gobernabilidad: un reportaje de América Latina. p. 96-7
} 
região andina. No entanto, não devemos esquecer que, em meados da década de 1990, tanto o governo norte-americano quanto o colombiano já vinham insistindo na existência de estreitos vínculos entre a guerrilha colombiana e os narcotraficantes. Nas palavras do presidente Ernesto Samper, a guerrilha colombiana tinha se "narcotizado" 28 , isto é, parte do financiamento da guerrilha das Farcs e ELN tinham como principal fonte de financiamento "os impostos de guerra" e o pagamento por proteção a plantios, laboratórios e carregamentos dos narcotraficantes. Essa estranha aliança entre guerrilha e narcotraficantes foi incorporada ao vocabulário político dos policy-makers de Washington e Bogotá como narcoguerrilha. Nem mesmo quando houve a militarização da repressão antidroga em países como Colômbia e Peru - que tinham como objetivo não-declarado o combate às forças guerrilheiras - tal política chegou a ser assumida de forma explícita.

Com o 11 de Setembro tal objetivo torna-se explícito, deslocando-se o foco do combate às drogas do narcotráfico para a guerrilha e grupos paramilitares atuantes na Colômbia. Em outras palavras, o combate de um passou significar o combate do outro. O que possibilitou essa mudança foi que, após os atentados terroristas, o governo de W. Bush deixou de diferenciar açôes de grupos guerrilheiros, paramilitares e narcotraficantes na região andina. $A$ guerra às drogas significava também a guerra ao terrorismo. A mudança conceitual levou ao entendimento de que a narcoguerrilha também daria espaço ao narcoterrorismo. A partir de então, tanto Washington quanto Bogotá começariam a pressionar os demais países andinos, assim como o Brasil, para que classificassem grupos como as Farcs como terroristas ${ }^{29}$.

Como justificativa política, a administração W. Bush havia feito um alerta, já no início de seu governo em 2001, sobre a falta de atenção de seus antecessores com relação ao conflito armado na Colômbia, que, segundo sua interpretação, "aliava o marxismo-leninismo aos benefícios da droga". Estava claro, portanto, que sua participação dentro do mesmo, segundo W. Bush, deveria contribuir para acabar com o tráfico de drogas, deter a guerrilha e colocar um ponto final na violência que rondava a região conhecida como "Triângulo Radical"30.

\footnotetext{
28 Tanto o governo Lula, no Brasil, como o de Hugo Chávez, na Venezuela, têm resistido a esses pedidos de certificação de terroristas da diplomacia norte-americana e, especialmente, no tocante à Colômbia.

${ }^{29}$ O norte-americano James Petras, no seu costumeiro estilo crítico, em seu ensaio intitulado "La Geopolítica del Plan Colombia”, assinala que depois que os EUA centralizaram sua atenção no Cone Sul durante a década de 1970, na América Central na década de 1980, passariam a entender que, a partir da década de 1990 e na virada do século, "o foco dos conflitos com o império encontrava-se na Colômbia, Venezuela e Equador (o chamado "Triângulo Radical")". Além disso, prossegue Petras, existiria um crescente descontentamento esquerdista e nacionalista nos países vizinhos importantes, como Brasil e Peru. Ver texto completo no site: http://wwwhazrebeldia.8m.com/plancol-petras $1 . \mathrm{htm}$

30 A distribuição dos recursos da Iniciativa Regional Andina, em ordem descrescente, é a seguinte: Colômbia (46\%), Peru (23,3\%), Bolívia (16,3\%), Equador (8,6\%), Brasil (3,2\%), Panamá $(2,2 \%)$ e Venezuela $(1,2 \%)$. Ver <http://www.ciponline.org/colombia/aid>.
} 
Além disso, a Administração W. Bush significou uma mudança não apenas de ênfase, mas sobretudo de direção no tratamento da questão colombiana à medida que o conflito passou a ser visto mais como questão global do que algo limitado à região andina e aos vizinhos colombianos. Concretamente, em 2001 a Administração W. Bush implementou a Iniciativa Regional Andina, que direcionava fundos não apenas para a Colômbia, mas também a outros países andinos, além do Brasil e Panamá. Posteriormente rebatizado de Iniciativa Andina Antidrogas, o programa obteve a aprovação no Congresso norteamericano para um orçamento de 700 milhôes de dólares para 2003 e de 731 milhões de dólares para 2004. No entanto, em ambos orçamentos, a prioridade dada à Colômbia era evidente: $63 \%$ dos recursos destinavam-se aos programas de erradicação e pulverização da droga em larga escala, assim como para o treinamento e compra de equipamentos militares, repartindo-se o restante entre Peru, Bolívia e Equador, nessa ordem ${ }^{31}$.

A partir da Iniciativa Regional Andina do Plano Andino (2001), uma tentativa de Bush em fornecer apoio financeiro aos países daquela região principalmente a região ao sul do Panamá, os EUA procuraram dar assistência a seus "aliados" (Colômbia, Equador, Bolívia), persuadir aos países "duvidosos" (Peru) e pressionar os "opositores" (Venezuela, Brasil e Argentina). O objetivo era estabelecer uma política comum contra o narcotráfico na Colômbia. Em termos reais, porém, a iniciativa significou a intensificação da pulverização dos cultivos de maconha, folha de coca e papoula, a proibição de carregamentos destinados aos EUA e a Europa, a extradição de condenados por narcotráfico e maior vigilância nos postos fronteiriços a fim de frear a movimentação de supostos terroristas de um país e para outro, o que gerava risco à segurança nacional.

Dessa forma, a estratégia de "empurrar para o sul" (Push in Southern) adotada pelo governo norte-americano em relação à Colômbia nos últimos anos traduziu-se na criação de três batalhōes antinarcóticos na área da selva das províncias de Putumayo, Caquetá e Guaviare. O objetivo era promover uma campanha de erradicação massiva de áreas de cultivo de folha de coca e papoula, que, a partir de 1992, simplesmente quadruplicaram, aumentando de 38 mil hectares para 136 mil em $2000^{32}$. Essa medida teve sérias conseqüências sobre a população e o meio ambiente, provocando o desaparecimento de mais de 8.100 hectares de floresta tropical. Por outro lado, as áreas de cultivo do narcotráfico ampliou-se para além das fronteiras colombianas, ocasionando sérios problemas aos países vizinhos.

\footnotetext{
31 De acordo com o orçamento de 1994, a Iniciativa Andina Antidrogas prevê algo em torno de 100 milhões de dólares para um fundo de saúde e desenvolvimento não relacionados com a droga. Os restantes - 731 milhōes de dólares - seriam destinados ao financiamento da erradicação, fumigação e interdição da droga, assim como para o reforço das leis e plantios alternativos. Ver <www.state.gov/m/ $/ \mathrm{mm} / \mathrm{rls} / \mathrm{cbj} /$ $2004>$.

32 OSTOS, María del Pilar. La Política de Estado de Estados Unidos en Colombia (1980-2004). Op. cit., p. 29.
} 
Adicionalmente, o governo colombiano implementou um amplo dispositivo de bases militares norte-americanas em substituição àquelas localizadas na área do Canal de Panamá, deslocando seu centro de comando para Base Aeronaval de Manta no Equador, no Oceano Pacífico. Essa base militar passou a ser assistida pela base holandesa de Curaçao, pelas bases da Libéria na Costa Rica, e Sotocano em Honduras. Estas, por sua vez, recebem apoio e proteção da base de Três Esquinas, Larandia e Puerto Legízamo, na província colombiana de Putumayo. As operaçôes conduzidas nessas bases militares são coordenadas pelos gigantescos e sofisticados radares de Guaviare e pelo sistema em Letícia, no Rio Amazonas. Além disso, o Peru planeja abrir aos EUA a base de Iquitos e o Brasil abriu negociações para a utilização da base de Alcântara, perto de Manaus, que conta com as bases dos satélites de Tabatinga, em frente à cidade de Leticia e Yavaraté, perto do Rio Negro.

Enfim, a novidade da Iniciativa Andina Antidrogas está exatamente no fato de que se apaga qualquer indício de estratégia diferenciada de combate a grupos guerrilheiros, paramilitares e narcotraficantes. "O Congresso [dos EUA] aprovou e a administração solicitou que se apagasse a linha que separa os programas antiterrorismo e antidrogas, permitindo que toda ajuda relativa à segurança fosse direcionada também ao combate às guerrilhas e aos paramilitares" 33 . Na prática, como observa o sociólogo colombiano Ricardo Vargas Meza, se até o 11 de Setembro o combate não-declarado às organizações guerrilheiras era justificado com o argumento de que a guerrilha representava um obstáculo para combater o narcotráfico (porque dependia dele e o protegia), a partir dos atentados terroristas tornou-se "legal a extensão dessa ajuda às atividades antiterroristas". 34

Entretanto, as diferenças em relação aos países vizinhos à Colômbia, que começam a se sentir mais profundamente afetados e imersos na dinâmica da expansão do conflito colombiano, cuja internacionalização tornou-se institucionalizada pelo Plano Colômbia e pela Iniciativa Andina Antidrogas.

\section{Colômbia e seus vizinhos: a ampliação das tensões regionais}

A implementação do Plano Colômbia e da Iniciativa Andina Antidrogas deram visibilidade a vários problemas entre vizinhos andinos, que até então permaneciam dormentes. Torna-se explícito o chamado "efeito balão". "O sucesso [do plano] na Colômbia repercute no Peru e na Bolívia, onde o cultivo da coca tem mostrado o primeiro crescimento em vários anos" 35 . Há evidências

\footnotetext{
33 INTERNATIONAL CRISIS GROUP. Colômbia e seus vizinhos: os tentáculos da instabilidade. Relatório sobre a América Latina, p. 7

${ }^{34}$ MEZA, Ricardo Vargas. Drogas, conflicto armado y seguridad global en Colombia. In: Nueva Sociedad. Caracas, no 192 , julio-agosto, p. 128.

35 International Crisis Group, op. cit., p. 6.
} 
de que o conflito na Colômbia seja um foco de irradiação de tensão regional, criando problemas de segurança nas fronteiras com todos os vizinhos (incluindo Brasil e Panamá, mas que não trataremos aqui por falta de espaço) por vários motivos.

Em primeiro lugar, porque o conflito entre os diversos grupos armados como os guerrilheiros da Farcs, os paramilitares das denominadas Autodefesas da Colômbia (AUC) e os grupos ligados aos narcotraficantes - pressionam as fronteiras colombianas com Equador, Peru e Venezuela. No caso desses três países, as zonas de cultivos de coca e de atuação dos grupos militares colombianos estão muito próximas de suas fronteiras. Quanto ao Equador, em sua fronteira norte com a Colômbia, especialmente na província de Sucumbios, podemos identificar atividades regulares de paramilitares da AUC na mesma região em que encontra-se o $48^{\circ}$ Destacamento das Farcs. Com a intensa militarização do Plano Colômbia e com a política de "segurança democrática" da administração Uribe, motivada por sua concepção de não distinguir o combate ao narcotráfico e do combate à guerrilha, os grupos guerrilheiros foram forçados a recuar progressivamente em direção ao território equatoriano, utilizando-o como retaguarda.

Adicionalmente, a proximidade do conflito acaba criando dois outros problemas graves para o Equador. De um lado, o aumento do tráfico de armas (e da comercialização de armas por drogas). "As fronteiras equatorianas são particularmente vulneráveis ao tráfico de drogas, armamentos e casos relacionados, devido à sua proximidade com os departamentos de Putumayo e Nariño [no sul da Colômbia], locais onde são cultivados $37 \%$ da coca no país". Além disso, "as autoridades militares colombianas queixam-se de que pelo menos $50 \%$ da munição que entra na Colômbia venha pelo Equador"36. De outro lado, os combates entre exército, paramilitares e guerrilha aumentaram o número de cidadãos desplazados (deslocados) para o território equatoriano em busca de segurança, empregos ou refúgio temporário. Somado ao fato de que a zona da fronteira com o Equador é altamente pobre e com sérios problemas de violência e criminalidade de todo tipo, o quadro é visto como altamente explosivo pelo governo equatoriano ${ }^{37}$.

Da mesma forma, podemos esperar problemas semelhantes nas fronteiras com Peru e Venezuela. No caso do Peru, foi descoberta, ainda no segundo mandato de Alberto Fujimori (1995-2001), uma grande rede de corrupção no interior das Forças Armadas, que serviriam de ponte para grupos de traficantes de armas negociarem com insurgentes colombianos, sejam

\footnotetext{
36 Ibid., p. 9.

37 Cf. AHUMADA, Consuelo Beltrán \& DURÁN, Álvaro Moreno. Prioridades del nievo orden mundial y desplazamiento forzado de colombianos hacia Ecuador. In: Cadernos do Prolam/USP. São Paulo: ano 3, vol. 1.
} 
guerrilheiros ou paramilitares ${ }^{38}$. Igualmente, ao longo dos $1.600 \mathrm{~km}$ da fronteira colombiano-peruana, funcionam laboratórios de morfina e cocaína. A fronteira entre Venezuela e Colômbia apresenta problemas similares aos do Equador e do Peru. A Venezuela, que compartilha uma fronteira de aproximadamente $2.000 \mathrm{~km}$ com a Colômbia, transformou-se na década de 1990 no "segundo ponto mais importante de embarque para a cocaína destinada aos EUA e à Europa"39. O tráfico de armas pela fronteira sudeste da Colômbia e o envolvimento de membros da Guardia Nacional da Venezuela nesse negócio ilícito também são fatores conhecidos na equação. Da mesma forma, acreditase na existência de acampamentos militares das Farcs e do ELN na fronteira sudeste, assim como de grupos paramilitares na fronteira sudoeste da Venezuela ${ }^{40}$. Finalmente, a Venezuela é o país de maior concentração de colombianos no mundo, com mais de 1,5 milhão de indivíduos. Com a certa intensificação do conflito na Colômbia, a situação dos deslocados criará novas pressōes nessas fronteiras.

Ainda que haja consenso entre os vizinhos colombianos acerca da interdependência entre assuntos de fronteiras, problemas de segurança, direitos humanos e corrupção nas forças armadas, parece haver um desacordo entre eles com relação à natureza do problema. Não há sinais de acordo sobre a hierarquia dos problemas e quanto à resolução dos mesmos. Para governos como o do Equador, Peru e Venezuela, a prioridade é a neutralização dos grupos insurgentes nas fronteiras, e não o combate ao narcotráfico ou o problema de segurança nacional. Ademais, nem todos concordam, como é o caso da Venezuela, em classificar todos esses grupos como narcoterroristas.

Finalmente, não podemos esquecer que existe, entre os vizinhos andinos da Colômbia, a preocupação de que o conflito colombiano possa gerar um spill-over de instabilidade regional, que possa afetar as relações bilaterais. Além disso, há o receio, por parte desses mesmos vizinhos, quanto às conseqüências sociais de uma intensificação do conflito nas fronteiras, sobretudo violência, desemprego e xenofobia. No caso do Equador, o aumento da entrada de migrantes voluntários, refugiados e deslocados "tem gerado uma certa xenofobia, assim como o aumento da delinqüência tem levado à expulsão de “indocumentados"(imigrantes ilegais sem documentos). Enfim, observamos,

38 QUIJANO, Aníbal. Las últimas elecciones del fujimorismo, in: Anuário Social y político de América Latina y el Caribe. Flacso/Nueva Sociedad, no 4.

39 International Crisis Group, op. cit., p. 14.

${ }^{40}$ Apesar do governo Chávez ter sido anfitriāo do encontro entre o governo colombiano e os representantes das Farcs e do ELN, e de ter participado do chamado Grupo de Facilitadores que mediou o processo de negociação de paz no governo de Andrés Pastrana, aconteceram seguidos atritos e incidentes na relação bilateral entre Colômbia e Venezuela. A deterioração das relações levaram o presidente venezuelano a declarar neutralidade no conflito, o que na prática significou reconhecer aos grupos rebeldes algum grau de legitimidade e capacidades de beligerância. A urgência insensata do governo Pastrana em reconhecer a legitimidade aos autores do golpe de abril de 2002 contra Hugo Chávez contribuiu também para aprofundar o clima de tensão entre Venezuela e Colômbia. 
hoje, a deterioração de uma boa relação que havia permitido conformar a primeira zona de integração no marco andino" ${ }^{41}$. Apesar do bom relacionamento entre o equatoriano Lúcio Gutiérrez e colombiano Álvaro Uribe em matéria de acordos econômicos e de integração fronteiriça ${ }^{42}$, e de posições comuns na relação comercial com os EUA (ambos estão negociando um acordo de livre comércio com Washington), o governo de Gutiérrez não apóia abertamente o Plano Colômbia pelos efeitos negativos que este pode gerar sobre o território equatoriano.

Quanto às relações bilaterais entre Colômbia e Venezuela, desde a declaração de neutralidade de Chávez sobre o conflito entre governo e guerrilha, ainda durante a presidência de Andrés Pastrana, surgiram críticas em meios oficiais colombianos ao governo venezuelano devido a sua ambigüidade em relação a grupos como as Farcs. Já no governo de Uribe, alguns senadores colombianos pediram à Organização dos Estados Americanos (OEA) a aplicação da Carta Democrática, enquanto que deputados venezuelanos denunciaram a existência de "uma corrida armamentista" na Colômbia. O último incidente diplomático entre ambos países aconteceu em meados de 2004, quando o governo venezuelano deteve em uma fazenda nas proximidades de Caracas um suposto grupo de paramilitares colombianos que, de acordo com o governo venezuelano, fariam parte de uma conspiração contra Hugo Chávez, em aliança com grupos locais de extrema direita, com financiamento vindo de grupos de interesse localizados em Miami. No entanto, ambos os lados concordaram em dar atenção à chamada "diplomacia do microfone", passando a recorrer com mais freqüência, sobretudo a partir do segundo semestre de 2004, à diplomacia presidencial direta. Como resultado, foram promovidos dois encontros presidenciais em menos de três meses, com a assinatura de acordos importantes em matéria energética e de infra-estrutura física.

No caso das relações bilaterais com o Peru, houve uma inversão no ânimo dos contatos diplomáticos. Superando a relação tensa durante o segundo mandato de Fujimori, os contatos diplomáticos entre Peru e Colômbia experimentaram uma melhora durante o governo de Alejandro Toledo ${ }^{43}$, que apóia o Plano Colômbia e a política de "segurança democrática" de Uribe. Toledo e Uribe assinaram um acordo de cooperação policial para combater as atividades ilícitas nas fronteiras comuns e para patrulhar conjuntamente o tráfego aéreo de narcóticos.

\footnotetext{
41 RAMÍREZ, Socorro. Op. cit., p. 153.

42 Ambos países assinaram em 1989 um acordo para a criação de uma Zona de Integração Fronteiriça.

43 Preocupado com sua reeleição para um terceiro mandato, Fujimori recorreu à manipulação da opinião pública nacional ao explicitar a ameaça que o conflito colombiano e o Plano Colômbia representavam para Peru. Seu objetivo, no entanto, era ocultar o envolvimento das Forças Armadas peruanas com o contrabando de armas para as Farcs e encobrir críticas quanto a violações de direitos humanos e à corrupção nas instituições sob o comando de seu chefe de inteligência Vladimiro Montesinos.
} 
Outro temor dos países andinos vizinhos à Colômbia, principalmente por parte da Venezuela que tem pendências fronteiriças ainda não resolvidas com a Colômbia, é que a farta ajuda militar norte-americana a seu vizinho possa originar um desequilíbrio militar regional ${ }^{44}$. Como observa Socorro Ramirez, "a presença de atores armados induz uma progressiva "geopolitização" e "securitização" de diversos temas nacionais e regionais" 45 .

Os governos andinos também passaram a enxergar com certa reserva as atitudes ambíguas da política de "segurança democrática" do presidente Uribe, sobretudo a relação dúbia no tratamento a paramilitares e guerrilha. Enquanto a um grupo é oferecido uma política de incentivos (carrots policy), ao outro lado, o porrete enérgico (sticks policy). Em outras palavras, o tratamento concedido por Uribe às Farcs e ao ELN parece ser mais duro do que àquele dado aos grupos paramilitares colombianos, aos quais é oferecido a possibilidade de incorporação à vida civil e política. Simultaneamente, tramita no Congresso colombiano uma lei de alternatividade penal, que prevê a criação de espaços de integração de paramilitares na vida civil, iniciativa considerada fundamental para fomentar as condiçôes para um cessar-fogo, desarmamento e possivelmente uma anistia de crimes passados.

Essa atitude ambígua tem levado certos setores a considerar que o governo Uribe utiliza os paramilitares como um instrumento de consolidação de zonas arrebatadas à guerrilha, no marco da política de "segurança democrática". "A maior crítica que se tem feito à execução da política [de Uribe] é que a recuperação de territórios pelo Exército é consolidada em várias regiōes pelos paramilitares" ${ }^{\prime 6}$. No entanto, esse é um problema dos mais difíceis de equacionar no sistema político colombiano exatamente porque o fenômeno do paramilitarismo na Colômbia está estreitamente vinculado às forças de segurança do Estado, especialmente do Exército colombiano, desde os anos 80. Esses grupos também contam com uma representação de deputados e senadores colombianos comprometidos com as suas causas. Conforme explica o cientista político colombiano Sanin, "os paramilitares têm elaborado nos últimos 20 anos uma densa rede de cumplicidade com organismos de segurança do Estado (...) [e também existem] fortes vínculos entre paramilitares e o poder político legal. Não só autoridades locais e regionais, mas também com congressistas e funcionários" $\$ 7$.

\footnotetext{
${ }^{44}$ Desde o governo de Rafael Caldera (1993-1998), a Venezuela mantém um acordo de vôos conjuntos sobre o território venezuelano que tem como objetivo identificar e interceptar aviōes utilizados para o tráfico de drogas. No início de seu governo, Hugo Chávez suspendeu a política de vôos de tripulação mista (Venezuela-EUA) sobre o território venezuelano, alegando serem incompatíveis com a soberania nacional. Posteriormente, voltou atrás, reiniciando os vôos de reconhecimento em setembro de 2002, após a visita de autoridades do Departamento de Estado para Assuntos Latino-americanos. Ver em El Universal de 28 de Setembro de 2002).

45 RAMÍREZ, Socorro. Op. cit., p. 145.

46 Cf. http://semana.terra.com.co/opencms/opencms/Semana/index.html, consultado em $11 \mathrm{dez} 2004$. 47 SANÍN, Francisco Gutiérrez. Ilegalidad y sistema político en Colombia: la agenda de Uribe Vélez. In: Nueva Sociedad. Caracas, no 192, julio-agosto, p. 68.
} 
Ainda sobre as relações da Colômbia com seus vizinhos, não podemos esquecer o lugar do Brasil, com o qual a Colômbia compartilha uma fronteira de $1.644 \mathrm{~km}$. Ao longo de boa parte de suas respectivas histórias, Brasil e Colômbia têm mantido uma política de quase indiferença recíproca. De acordo com Marta Ardilla, o Brasil "pouco se interessava pela Colômbia e menos ainda por sua fronteira devido ao distanciamento comercial e cultural” 48 . Com relação às convergências externas, podemos, no entanto, destacar três pontos. Como os dois principais produtores mundiais de café, lideraram a criação da Associação de Países Produtores de Café em 1993, através da qual tentaram recuperar os preços internacionais do produto, em desvalorização contínua desde o final da década de 1980. Destacamos também que, ao longo das décadas de 1980 e 1990, ambos negociaram uma agenda sobre cooperação judicial, policial e militar no combate ao narcotráfico, que resultou na assinatura, em 1981, de um acordo antidrogas e, em 1991, de um ajuste complementar sobre cooperação judiciária. No entanto, tais iniciativas podem ser consideradas como insuficientes.

No plano político, Brasil e Colômbia têm visões divergentes em dois pontos: o Plano Colômbia, o que implica em discordância acerca das relaçóes com os EUA, e o lugar do Brasil no processo de negociação de paz. O Plano Colômbia, de iniciativa norte-americana e implementada durante o governo Pastrana, é visto com muita reserva pelos formuladores da política externa brasileira, que suspeitam de uma militarização das regióes andina e amazônica a partir da Colômbia. "Para o Brasil, quatro observaçōes sobre possíveis desdobramentos do Plano Colômbia podem ser ressaltadas: a) não se aceita eventual transferência do teatro de operaçóes de qualquer ator armado para o território brasileiro; b) refuta-se qualquer participação militar no conflito colombiano; c) mesmo entendendo que a probabilidade de cenários adversos para a Amazônia brasileira é pequena, o Brasil procura proteger-se de eventuais desdobramentos; e d) o aprimoramento da capacidade de resposta dos órgãos estatais brasileiros na Amazônia se dá exclusivamente nesse contexto defensivo“49.

Finalmente, um importante ponto de divergência desenvolve-se com respeito à participação do Brasil no processo de negociação de paz colombiano. A posição oficial do governo brasileiro pode ser resumida da seguinte forma: a) a busca de uma saída negociada ao conflito; b) a adoção da mediação internacional do conflito, observado o princípio de não-intervenção, devendo a mediação ocorrer a partir de solicitação formal da Colômbia; c) recusa de reconhecimento das Farcs e outros grupos guerrilheiros como terroristas.

\footnotetext{
${ }^{48}$ ADILLA, Marta. La política exterior de Colombia hacia sus vecinos. Evolución, mecanismos y retos. In: ARDILlA, Marta, CARDONA, Diego e TICNER, Arlene (eds.). Prioridades e desafios de la politica exterior colombiana. 2002, p. 332.

${ }^{49}$ CASTRO, André Dunhan Maciel Sianes de. A crise na Colômbia: impactos e implicaçōes para o Brasil. Brasília: Tese de Mestrado, Instituto Rio Branco. p. 72-5.
} 
Durante o governo Pastrana, houve um intenso processo de negociação com as Farcs, as quais foram concedidas uma zona desmilitarizada de quase $40 \%$ do território nacional. Um ator importante no processo de negociação, durante os anos Pastrana, foi a "Comissão de Países Facilitadores para o Processo de Paz", composto por Cuba, Espanha, França, Itália, México, Noruega, Suécia, Suíça e Venezuela. O Brasil esperou, quase que ansiosamente, o convite do governo colombiano para participar desse grupo, o que nunca ocorreu ${ }^{50}$.

No entanto, com a chegada ao poder dos presidentes Uribe e Lula na Colômbia e no Brasil, respectivamente, houve uma maior aproximação de visões com relação ao conflito, embora as divergências nos outros pontos mencionados acima ainda se mantenham. No intervalo de um ano, o presidente Uribe visitou o Brasil em duas oportunidades e o governo brasileiro ofereceu o seu território para um diálogo entre o governo colombiano e as Farcs, além de propor a mediação do secretário-geral da ONU no conflito. Dessa forma, a questão colombiana acabou por assumir, nas palavras de alguns formuladores da política externa brasileira, "um patamar de altíssima prioridade" 51.

Conforme sustentado por um estudioso brasileiro da crise colombiana, "A força das posições dos EUA implica em obstáculos ao projeto de integração sul-americana proposto pelo Brasil (...) Os objetivos e estratégias dos EUA podem não estar atendendo nem aos seus próprios interesses e certamente não atendem aos do Brasil, que são o equacionamento do conflito político, o investimento em democracia como forma de combater o conflito interno" 52 .

Para os formuladores da política externa brasileira, a promoção da democracia na região é interpretada como um caminho viável para atingir, ou pelo menos atenuar, os problemas de segurança regional que podem decorrer da "militarização da política regional andina". Significa também o esvaziamento da diplomacia e das possibilidades da negociação. As posições brasileiras, ao contrário, defendem a negociação e o entendimento pacífico" 53 .

\section{Conclusão}

A agenda de segurança dos EUA para Colômbia - consubstanciada nas ações do Plano Colômbia e da Iniciativa Regional Andina - continuará sendo a pedra basilar da ação norte-americana na região, até porque desfruta de um sólido consenso entre democratas e republicanos. Segundo os decision-makers norte-americanos, ambas iniciativas revelam-se submetidas à lógica da segurança

\footnotetext{
${ }^{50} \mathrm{CEPIK}$, Marco. A politica externa de Lula: desafios do primeiro ano e a questão colombiana. Mimeo. Documento preparado por solicitação do International Crisis Group (ICG).

51 Conforme declaração do ministro das Relaçōes Exteriores no governo Lula, Celso Amorin. Ver site do Senado Federal: < www. senado.gov.br>.

52 CASTRO, André Dunhan Maciel Sianes de. op. cit., p. 69-70.

53 Ibid., p. 71.
} 
nacional por três motivos: primeiro, a Colômbia continua a ser o principal centro produtor de cocaína no mundo e o país que ainda tem as guerrilhas mais ativas na América Latina; segundo, devido a sua proximidade territorial tanto com a Venezuela - principal fornecedor ocidental de petróleo aos EUA - quanto com o Canal do Panamá; e terceiro, devido ao nível de satisfação da Administração W. Bush com os resultados obtidos pela política de "segurança democrática" de Uribe no campo militar e político frente às guerrilhas das Farcs. Além disso, de forma que os EUA deixariam de ignorar a oportunidade de liquidar com a mais antiga e resistente guerrilha latino-americana.

Finalmente, sobre as relaçóes da Colômbia com seus vizinhos, devemos salientar o caráter "interméstico" das mesmas, em que problemas da agenda doméstica são internacionalizados, tendo um impacto sobre a definição interna de estratégias políticas e militares. Nesse caso, torna-se possível afirmar que, no caso dos países vizinhos à Colômbia, os problemas da agenda doméstica colombiana foram regionalizados de tal forma que o conflito armado interno passou a ser um foco de irradiação de tensão em toda a região.

No entanto, em um passado recente, existiu - e é muito provável que continue a existir no futuro - uma forte divergência de concepção entre as elites dirigentes na Colômbia e seus aliados norte-americanos, e a maioria dos países andinos acerca do impacto e forma de tratamento da questão colombiana. Enquanto que para a Colômbia e os EUA o combate ao narcotráfico e à guerrilha constitui um problema de segurança nacional e regional, cuja solução necessariamente dar-se-á pela internacionalização e militarização do conflito, para a maior parte dos países da região, o tratamento poderia ser mais eficaz se o conflito fosse tratado de forma mais bilateral e pontual. Conforme lembra Bonilla, "as ameaças são percebidas a partir de cenários nacionais e não regionais" 54 .

Os outros países da região andina entendem que existem seis problemas "intermésticos": o plantio e o tráfico de drogas, a atuação de atores armados, a questão dos direitos humanos, os deslocamentos forçados, as possibilidades de desastres ecológicos, e a lavagem de dinheiro. No entanto, a maioria dos países andinos, embora reconheçam esses problemas, não querem fazer parte deles, seja por falta de capacidade ou pelo cálculo político sobre riscos e benefícios.

Recebido em 13 de setembro de 2005 Aprovado em 20 de outubro de 2005

\footnotetext{
54 BONILLA, Adrián. Vulnerabilidad internacional y fragilidad doméstica: la crisis andina en perspectiva regional. In: Nueva Sociedad. Caracas, no 51, mayo-junio, 2001, p. 60.
} 


\section{Referências bibliográficas}

ANZOLA, Libardo Sarmiento Libardo. O Plano Colombia e a economia política da guerra. Política Externa, vol. 9, n.3. São Paulo/USP/Paz e Terra, dez-jan, 2000/2001.

ARDILLA, Marta. La política exterior de Colombia hacia sus vecinos. Evolución, mecanismos y retos. in ARDILLA, Marta, CARDONA, Diego e TICNER, Arlene (eds.). Prioridades e desafios de la politica exterior colombiana. Bogota: Friedrich Ebert, 2002.

BONILLA, Adrián. Percepciones de la amenaza de seguridad nacional de los países andinos: regionalización del conflicto colombiano y narcotráfico. in GÓMEZ, José Maria (Comp.). América Latina y el (des)orden global neoliberal. Hegemonía, contrahegemonía, perspectivas. Buenos Aires: CLACSO, 2004.

Adrián. Vulnerabilidad internacional y fragilidad doméstica: la crisis andina en perspectiva regional. Nueva Sociedad, no 51. Caracas, mayo/junio, 2001.

BELTRÁN, Consuelo Ahumada \& DURÁN, Álvaro Moreno. Prioridades del nievo orden mundial y desplazamiento forzado de colombianos hacia Ecuador. Cadernos do PROLAN/ USP, Ano 3, Vol. 01. São Paulo, 2004.

CASTRO, André Dunhan Maciel Sianes de. A crise na Colômbia: Impactos e Implicaçôes para o Brasil. Tese de Mestrado. Brasília: Instituto Rio Branco, 2003.

CEPIK, Marco. A política externa de Lula: desafios do primeiro ano e a questão colombiana. Mimeo. Documento preparado por solicitação do International Crisis Group (ICG), 2002.

CIMADAMORE, Alberto. La política antidrogas de EE.UU. Condiciones internas y efectos intra-hemisféricos. Cuadernos de Nueva Sociedad, no 1 . Caracas, $2^{\circ}$ semestre, 1997.

FRANCO, Andrés. (ed.). Estados unidos y los paises andinos, 1993-1997: poder y desintegración. Facultad de Ciencias Políticas y Relaciones Internacionales. Pontificia Universidad Javeriana. Bogotá. 1998.

GARCIA, Andelfo. Plan Colombia y ayuda estadounidense. in El Plan Colombia y la Internacionalización del conflicto. Instituto de estudios Políticos y Relaciones Internacionales (IEPRI). Universidad Nacional de Colombia. Editorial Planeta. Bogotá.

GARRIDO, Roberto Soberón.”Entre cuarteles, caletas y fonteras. Cuadernos de Nueva Sociedad, no 1 . Caracas, 20 semestre, 1997.

INTERNATIONAL CRISIS GROUP. Colômbia e seus vizinhos: os tentáculos da instabilidade. Relatório sobre a América Latina. Bogota: IGC, 2003.

KENNEDY, Paul. Preparando para o século XXI. Rio de Janeiro: Editora Campus, 1993.

LEONGÓMEZ, Eduardo Pizarro. Una luz al final del tunel. Balance estratégico del conflicto armado en Colombia. Nueva Sociedad, n. 192.Caracas, jul-ago, 2004.

LESSMANN, Roberto. El narcotráfico y las relaciones internacionales. Cuadernos de Nueva Sociedad, n. 1. Caracas, 2o semestre, 1997.

MEZA, Ricardo Vargas. Drogas, conflicto armado y seguridad global en Colombia. Nueva Sociedad, n. 192. Caracas, julio-agosto, 2004.

OSTOS. Maria del Pilar. Continuidad o cambio? La participación de México en el conflicto armado colombiano. Mimeo. Cidade de México, 2005.

Maria del Pilar. La Política De Estado de Estados Unidos en Colombia (1980-2004).

Mimeo. Cidade de México, 2005. 
QUIJANO, Aníbal. Las últimas elecciones del fujimorismo. in Anuário Social y político de América Latina y el Caribe. Flacso/Nueva Sociedad, no 4, 2001.

RAMÍREZ, Socorro. Colombia y sus vecinos. Nueva Sociedad, n. 192. Caracas, julio-agosto, 2004.

RESTREPO, Luis Alberto. La difícil recomposición de Colombia. Nueva Sociedad, n. 192. Caracas, julio-agosto, 2004.

RODRIGUES, Thiago. Narcotráfico: uma guerra na guerra. São Paulo: Editora Desatino, Série Elementos, 2003.

ROJAS, Diana Marcela e LEON, Adolfo A. El Proceso de paz y el Plan Colombia. in El Plan Colombia y la Internacionalización del conflicto. Bogotá: Instituto de Estudios Políticos y Relaciones Internacionales (IEPRI). Universidad Nacional de Colombia. Editorial Planeta, 2001.

SAMPER, Ernesto. Ernesto Samper: gobernabilidad sin soberanía no vale la pena. In: ARCHARD, Diego e FLORES, Manuel. Gobernabilidad: un reportaje de América Latina. México:_PNUD/Fondo de Cultura Económica, 1997.

SANIN, Francisco Gutiérrez. Ilegalidad y sistema político en Colombia: la agenda de Uribe Vélez. Nueva Sociedad, n. 192. Caracas, julio-agosto, 2004.

TOKATLIÀN, Juan Gabriel. El plan Colombia. De la Guerra interna la intervención internacional? Anuario Social y político de América Latina y el Caribe. Flacso/Nueva Sociedad, no 4, 2001.

ULLOA, Fernando. Álvaro Uribe: dissidente. Política Externa, n.12, vol. 2. São Paulo: USP/ Paz e Terra, [set/nov, 2003.

VILLA, Rafael Duarte. Da Crise do realismo á segurança global multidimensional. São Paulo, Annablueme/Fapesp, 1999.

\section{Resumo}

Este artigo trabalha a tese de que a agenda de segurança dos EUA para Colômbia, que adquire expressão concreta em mecanismos como o Plano Colômbia e a Iniciativa Regional Andina, continuará sendo o eixo central da política de segurança na região sul-americana. No entanto, a noção de segurança que têm em mente os decisions makers dos EUA no caso colombiano reflete uma visão nas percepções de ameaças na que se misturam fortemente elementos novos ("as novas ameaças"), como o tráfico de drogas e fatores clássicos.

\section{Abstract}

This article works the thesis that the security agenda of the USA for Colombia, that acquires a concrete expression in mechanisms like the Colombia Plan and the Andean Regional Initiative, will remain as the central axis of the security policy in the SouthAmerican region. However, the notion of security that the decision makers of the USA have in mind in the Colombian case reflects a vision focused on the perceptions of threat in which new elements ("the new threats"), such as traffic, and classical factors are mixed.

Palavras-chave: Colômbia, EUA, Agenda de Segurança, Plano Colômbia, Narcotráfico, Farcs. Key words: Colombia, US, Security Agenda, Plan Colombia, Drug trafficking, Farcs. 